\title{
Editorial
}

\section{Direct Alcohol Fuel Cell}

\author{
Changwei Xu, ${ }^{1}$ Pei-Kang Shen, ${ }^{2}$ Dingsheng Yuan, ${ }^{3}$ and Shuangyin Wang ${ }^{4}$ \\ ${ }^{1}$ School of Chemistry and Chemical Engineering, Guangzhou University, Guangzhou 510006, China \\ ${ }^{2}$ School of Physics and Engineering, Sun Yat-Sen University, Guangzhou 510275, China \\ ${ }^{3}$ Department of Chemistry, Jinan University, Guangzhou 510632, China \\ ${ }^{4}$ Department of Chemical Engineering, Case Western Reserve University, Cleveland, OH 44106, USA
}

Correspondence should be addressed to Changwei Xu, cwxu@gzhu.edu.cn

Received 24 November 2011; Accepted 24 November 2011

Copyright (C) 2011 Changwei Xu et al. This is an open access article distributed under the Creative Commons Attribution License, which permits unrestricted use, distribution, and reproduction in any medium, provided the original work is properly cited.

Fuel cells are of tremendous interest, from both energy and environmental points of view. Fuel cells convert chemical energy directly into electrical energy with high efficiency and low emission of pollutants, may help to reduce the dependence on fossil fuels, and operating without combustion, and can contribute to reduce environmental impact. Fuel cells are a practical answer to the world's pressing need for clean and efficient power. Direct alcohol fuel cell (DAFC) fuel has attracted enormous attention as power source for portable electronic devices and transportation due to the much higher energy density than gaseous fuels such as hydrogen and natural gas. Pt has been extensively investigated as the electrocatalyst for methanol and ethanol electrooxidation. However, the high price and limited supply of Pt constitute a major barrier to the development of DAFCs: the development of Pt-free electrocatalysts for alcohol oxidation and the development of other metal-oxidemodified Pt electrocatalysts.

This special issue on focuses on the DAFCs. The authors have focused on reporting the alcohol oxidation on Pt-free and Pt-based electrocatalyst and the optimization of DAFCs. Here, the Pt-free electrocatalysts for alcohol oxidation are $\mathrm{Ni}$ based electrocatalysts in alkaline medium. The development of other metal-oxide-modified Pt-electrocatalysts is $\mathrm{Pd}$, $\mathrm{SnO}_{2}$-modified Pt. The authors have given good results to increase the electrocatalyst activity and thus to reduce the usage of the Pt. Other authors have studied the oxygen reduction reaction and alcohol supply optimization in the DAFCs. The results will contribute to the development of DAFCs. 


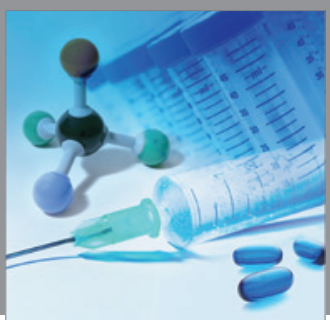

International Journal of

Medicinal Chemistry

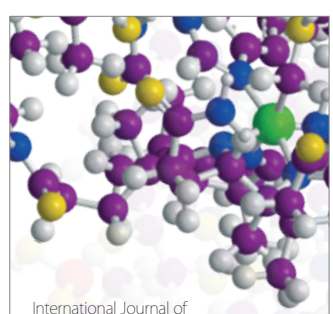

Carbohydrate Chemistry

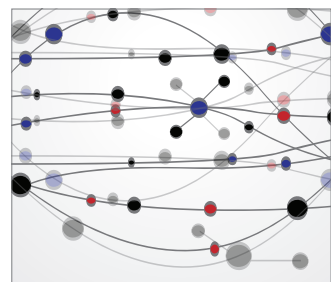

The Scientific World Journal
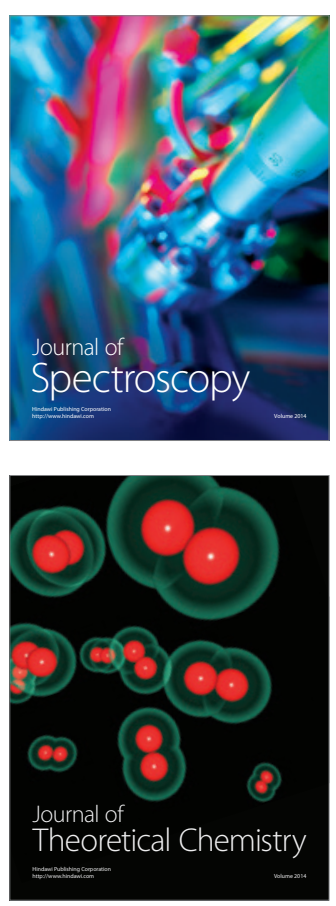
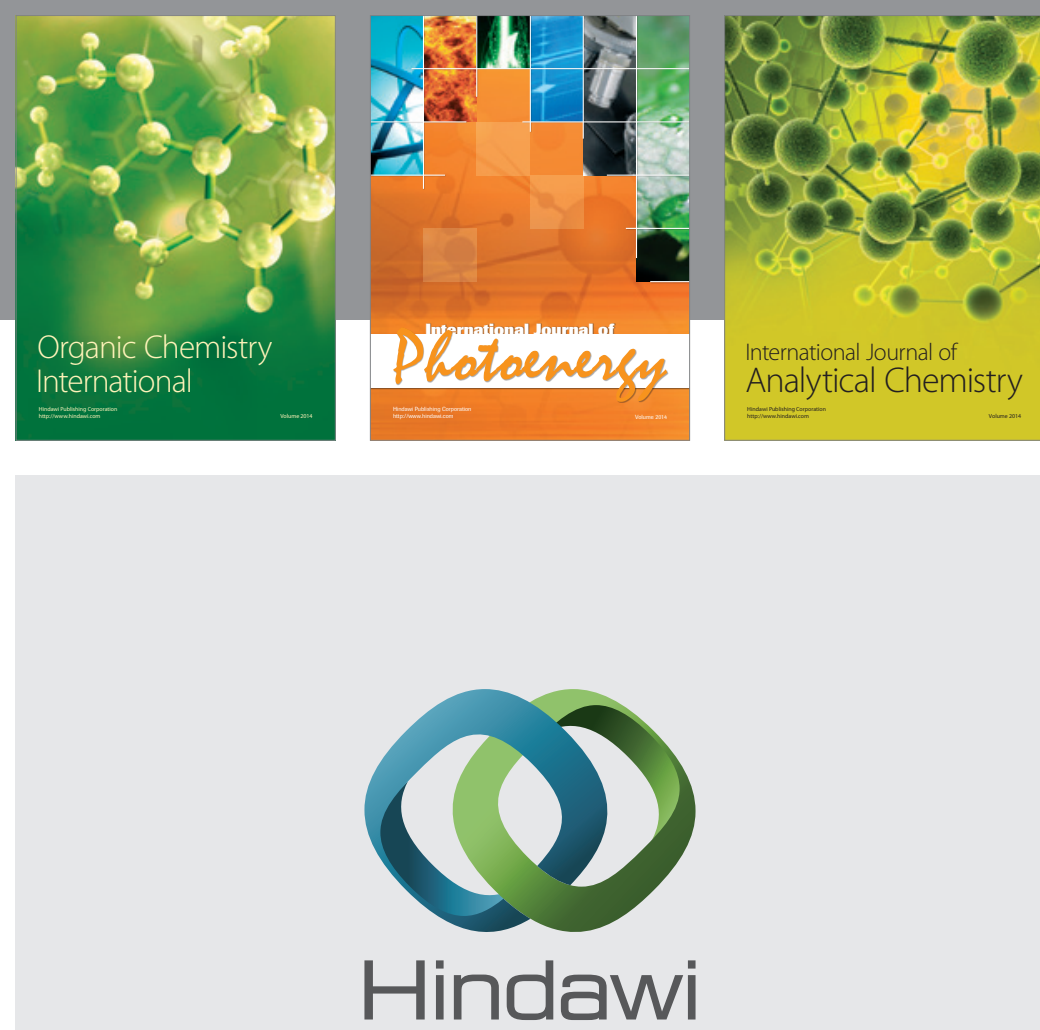

Submit your manuscripts at

http://www.hindawi.com
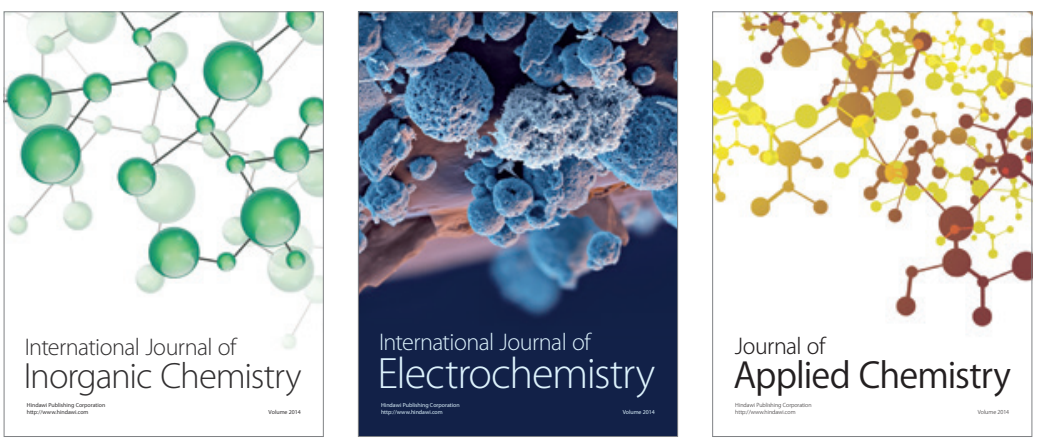

Journal of

Applied Chemistry
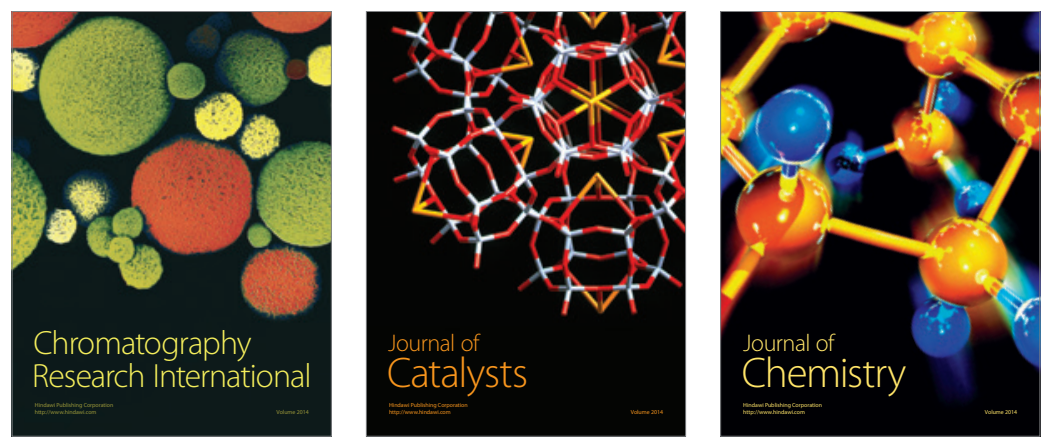
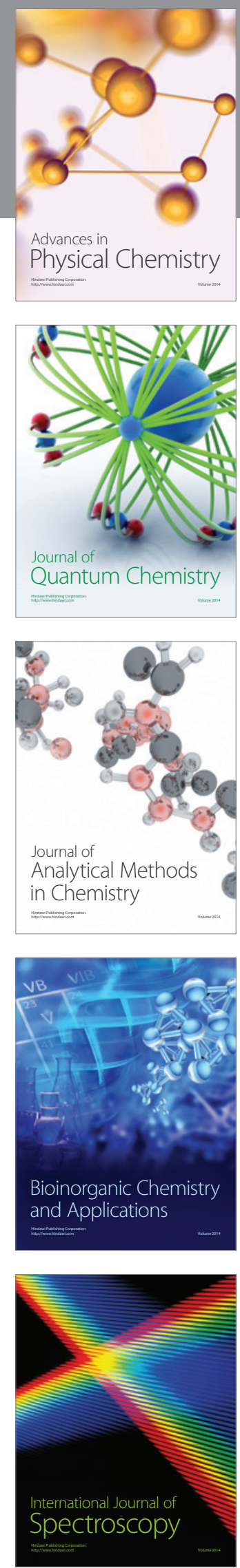